\title{
Chronic Toxicity Test in Cynomolgus Monkeys For 98 Days with Repeated Intravenous Infusion of Cynomolgus Umbilical Cord Mesenchymal Stem Cells
}

\author{
Jie He ${ }^{a, b, c}$ Guang-ping Ruan ${ }^{a, b, c}$ Xiang Yao ${ }^{a, b, c}$ Ju-fen Liua, ${ }^{a, b, c}$ Xiang-qing Zhu $u^{a, b, c}$ \\ Jing Zhao ${ }^{a, b, c}$ Rong-qing Pang ${ }^{a, b, c} \quad Z i$-an Lia, ${ }^{a, b}, c \quad$ Xing-hua Pan ${ }^{a, b, c}$ \\ aKunming Key Laboratory of Stem Cell and Regenerative Medicine, Kunming General Hospital of \\ People's Liberation Army, Kunming, 'Stem Cells and Immune Cells Biomedical Techniques Integrated \\ Engineering Laboratory of State and Regions, Kunming, 'Cell Therapy Technology Transfer Medical Key \\ Laboratory of Yunnan Province, Kunming, China
}

\section{Key Words}

Umbilical cord mesenchymal stem cells • Preparation • Quality identification • Chronic toxicity test

\begin{abstract}
Background/Aims: Stem cell-based therapy is attractive in many clinical studies, but current data on the safety of stem cell applications remains inadequate. This study observed the safety, immunological effect of cynomolgus monkey umbilical cord mesenchymal stem cells (mUCMSCs) injected into cynomolgus monkeys, in order to evaluate the safety of human umbilical cord mesenchymal stem cells (hUC-MSCs) prepared for human clinical application. Methods: Eighteen cynomolgus monkeys were divided into three groups. Group 1 is control group, Group 2 is low-dose group, Group 3 is high-dose group. After repeated administrations of mUC-MSCs, cynomolgus monkeys were observed for possible toxic reactions. Results: During the experiment, no animal died. There were no toxicological abnormalities in body weight, body temperature, electrocardiogram, coagulation and pathology. In the groups 2 and 3, AST and CK transiently increased, and serum inorganic $P$ slightly decreased. All animals were able to recover at 28 days after the infusion was stopped. In the groups 2 and 3, CD3+ and IL- 6 levels significantly increased, and recovery was after 28 days of infusion. There were no obvious pathological changes associated with the infusion of cells in the general and microscopic examinations. Conclusions: The safe dosage of repeated intravenous infusion of mUC-MSCs in cynomolgus monkeys is $1.0 \times 10^{7} / \mathrm{kg}$, which is 10 times of that in clinical human use.
\end{abstract}




\section{Cellular Physiology Cell Physiol Biochem 2017;43:891-904 \begin{tabular}{ll|l} 
and Biochemistry Published online: September 29, 2017 & $\begin{array}{l}\text { (c) } 2017 \text { The Author(s). Published by S. Karger AG, Basel } \\
\text { www.karger.com/cpb }\end{array}$ \\
\hline
\end{tabular}}

He et al.: Chronic Toxicity Test of Muc-Mscs

\section{Introduction}

Umbilical cord mesenchymal stem cells (UC-MSCs) derived from colloid connective tissues of the umbilical cord have attracted much attention in recent years due to their multi-directional differentiation potential, and anti-inflammatory and immunoregulatory properties [1-3]. In 2003, Mitchell [2] successfully cultured mesenchymal stem cells from human umbilical cord tissues using the tissue culture method. Furthermore, researchers have routinely used the tissue adherence procedure, in which cells underwent enzymatic digestion and were cultured in uniform and stable UC-MSCs, allowing cells to exhibit their self-renewal ability [4-7]. When cells were subcultured for more than 80 generations, no indication of aging or change in morphology was observed. Compared with bone marrow- and adipose-derived mesenchymal stem cells, UC-MSCs have obvious advantages. The umbilical cord is considered as waste after delivery. Hence, it is easy to collect and a convenient source, it is harmless to donors, and it is free from ethical restriction. For characteristics of better stemness and activity, these cells have the activity and biological characteristics of stability after freezing and resuscitating. Furthermore, the effect to some diseases are obvious, including liver damage, spinal cord injury, degenerative disease, graft-versus-host disease (GVHD) and autoimmune diseases [8, 9]. UC-MSCs are thought to have promising clinical application because of their high proliferative potential and ease of isolation than MSCs from other sources [10]. This is expected to become a large-scale production of "stem cell drugs."

At present, many studies have reported on the preparation and treatment of UC-MSCs. However, these reports have not established the preparation and identification of technical specifications and quality control standards. UC-MSCs are a new type of biological agent, and the production and preparation of each link may affect the quality of its preparation. The quality of its preparation also directly determines its clinical safety and effectiveness. Hence, there is a need to determined for a standardized production and preparation protocol for each link [11]. This study intends to establish a simple, stable and efficient preparation standard for cynomolgus UC-MSCs (mUC-MSCs), as well as a quality control standard of clinic-grade mUC-MSCs that can be directly resuscitated and reinfused. These shall be the results of future clinical trials and related studies, providing the technical or standardized formulation of mUC-MSCs.

Human umbilical cord mesenchymal stem cells (hUC-MSCs) are one of the typical adult stem cells; they have superiorities including low immunogenicity, non-invasive harvest procedure, and easy expansion in vitro and ethical access compared with stem cells from other sources. Therefore, hUC-MSCs are a promising candidate for cell-based therapy [12].

hUC-MSCs seem to be an optimal choice for stem cell-based therapy. However, before the cells translate from basic to clinical research, some problems still remain to be solved: i) building regulatory guidelines as well as an efficient and safe manufacturing procedure; ii) establishing donor's genetic testing and long-term closely monitoring system; iii) conducting further clinical trials to determine the optimum and standard dosage, time, route, frequency and many other technical issues of hUC-MSCs transplantation [12]. Due to the potential therapeutic mechanisms, as well as challenges of hUC-MSCs in clinical translation, we used mUC-MSCs from monkeys for this experiment to imitate hUC-MSCs used for human.

With the extensive application of UC-MSCs, especially in the preparation of UC-MSC products in clinic, we must take safety as a prerequisite. This study aimed to conduct a safety evaluation on the preparation of the proposed mUC-MSCs. The cynomolgus monkey is a nonhuman primate, and has a close relationship with humans. It is highly similar to humans in terms of tissue structure, pathophysiology, immune regulation and energy metabolism. Its research value is obviously superior to that of other species [13]. This study aimed to establish a culture method for mUC-MSCs, and evaluate the safety of mUC-MSCs through repeated intravenous infusion treatments in cynomolgus monkeys. These study results would lay a foundation for the basic research of UC-MSCs and provide guidance in clinical treatment. 


\section{Cellular Physiology Cell Physiol Biochem 2017;43:891-904

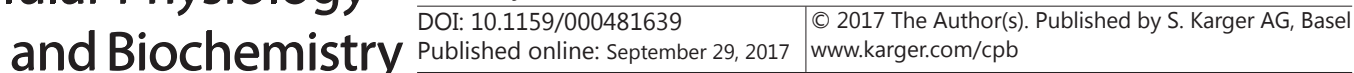

He et al.: Chronic Toxicity Test of Muc-Mscs

\section{Materials and Methods}

\section{Ethics approval and consent to participate}

The experimental protocols were approved by the Experimental Animal Ethics Committee of Kunming General Hospital of the PLA (Ref. 2015003).

\section{Isolation, culture and identification of mUC-MSCs}

Isolation and culture of mUC-MSCs. Under sterile conditions, umbilical cords were collected from monkeys and rinsed with a double anti-solution containing $100 \mathrm{U} / \mathrm{ml}$ of penicillin and $100 \mathrm{mg} / \mathrm{ml} \mathrm{of}$ streptomycin to remove residual blood. Then, the umbilical cord was subdivided into $1-\mathrm{mm}^{3}$ tissue sections. Each tissue section was transferred into $1.5 \mathrm{ml}$ EP tubes, the tissues were separated by iris shearing, and the paste was transferred to culture flasks. A 3 ml aliquots of 10\% FBS containing DMEM/F12 medium was used to allow the tissues to be evenly distributed, and the tissues were cultured in an incubator with $5 \% \mathrm{CO}_{2}$ at $37^{\circ} \mathrm{C}$. The liquid was changed after five days and every 3-4 days thereafter, and tissues that adhered and grew on the wall were observed. After cells crawled out of the tissues and grew to $80 \%-90 \%$ of the fusion state, these cells were digested with $0.25 \%$ trypsin-EDTA. Then, the eluted tissue mass was inoculated with a new culture flask. For the second tissue mass that adhered to the wall, cells also crawled out of the tissue and grew to $80 \%-90 \%$ of the fusion state. These cells were digested with $0.25 \%$ trypsin-EDTA. Tissue pieces that eluted after the second tissue adherence were inoculated in a new culture flask, performing the third organization of adherent culture. The experimental protocol was approved by the Experimental Animal Ethics Committee of Kunming General Hospital of the PLA (Ref. 2015003).

Cryopreservation and resuscitation of mUC-MSCs. Cryopreservation: The logarithmic growth phase of mUC-MSCs digested with $0.25 \%$ trypsin-EDTA was selected. Then, cells were centrifuged to remove the trypsin-EDTA and old culture medium, the prepared frozen culture medium was added (containing 10\% DMSO and 5\% glycerol), and the concentration of cells in the cryopreservation solution was maintained at $4 \times 10^{6}$ cells $/ \mathrm{ml}$. Subsequently, cells were gently blown using a straw, placed into a sterile cryopreservation tube, and $1.8 \mathrm{ml}$ was added into each frozen tube. The frozen tubes indicated the cell name, lot number and cryopreservation time, and record was prepared. The cryopreserved tubes that contained the cells were place in the programmed cooling box of the refrigerator at $-70^{\circ} \mathrm{C}$. After four hours, the tubes were placed in a liquid nitrogen tank at $-196^{\circ} \mathrm{C}$.

Cell resuscitation: The mUC-MSC frozen tubes were removed from the liquid nitrogen can, quickly placed in a $37^{\circ} \mathrm{C}$ water bath, and the cryopreservation tube was continuously shaken to allow the cell suspension to rapidly melt. When the cell suspension completely melted, in a clean bench, >10 times of the volume of saline was added, centrifuged at low speed, remove the supernatant, and washed twice with basic medium. Trypan blue staining was performed to detect for cell viability and counts. After inoculation in the culture flask, cells were placed in an incubator with $5 \% \mathrm{CO}_{2}$ at $37^{\circ} \mathrm{C}$.

Immunophenotyping of mUC-MSCs. CD34-PE, CD44-FITC, CD45-PC5, CD90-FITC, CD29-FITC and $10 \mu \mathrm{l}$ of isotype control were added to each of the third passage cells (P3) with $1 \times 10^{6}$ cells per tube, and washed three times. Cells were incubated at $4^{\circ} \mathrm{C}$ for 30 minutes in the dark, washed with phosphate buffer to discard the unbound antibodies, and the expression level of the surface antigen was detected by flow cytometry.

Detection of mUC-MSC differentiation ability. Adipose-induced differentiation: P3 cells were digested, $1 \times 10^{4}$ cells $/ \mathrm{cm}_{2}$ was inoculated into 12 -well plates, and the 10\% FBS DMEM/F12 culture medium were discarded when cells reached $100 \%$ fusion. For the lipid differentiation-induced fluid culture, the fluid was replaced every three days. After culture for 14 days, cells were fixed with $4 \%$ paraformaldehyde, oil red 0 was added, and cells were observed under a microscope.

Osteogenic differentiation: P3 generation cells $\left(5 \times 10^{3} / \mathrm{cm}^{2}\right)$ were inoculated into a 12 -well plate until $60 \%$ of the cell fusion state was attained, the culture medium was discarded, osteogenic induction fluid was added for continuous culture, and the fluid was replaced every three days. After 21 days of culture, cells were fixed in $4 \%$ paraformaldehyde, alizarin red was added, and cells were observed under a microscope.

Cartilage differentiation: P3 cells were collected, density was adjusted to $1 \times 10^{7} / \mathrm{ml}, 5 \mu \mathrm{l}$ was taken and inoculated into a 12 -well plate, placed in an incubator for two hours with $5 \% \mathrm{CO}_{2}$ at $37^{\circ} \mathrm{C}$, preheat cartilage differentiation culture medium standing culture was slowly added, and the fluid was replaced every three days. After 14 days of incubation, the cells form a pelletized pellet, cells were fixed in $4 \%$ paraformaldehyde, paraffin-embedded chondrocytes were pelletized, the sections were stained with dexamethasone, and 


\section{Cellular Physiology Cell Physiol Biochem 2017;43:891-904 \begin{tabular}{l|l|l}
\hline DOI: 10.1159/000481639 & $\begin{array}{l}\text { C } 2017 \text { The Author(s). Published by S. Karger AG, Basel } \\
\text { www.karger.com/cpb }\end{array}$
\end{tabular} \\ He et al.: Chronic Toxicity Test of Muc-Mscs}

cells were observed under a microscope.

\section{Chronic toxicity test}

Animal grouping. Male $(\mathrm{n}=9)$ and female $(\mathrm{n}=9)$ segments, and random numbers were assigned for each segment using the Excel software.

Table 1. Animal groupings and infusion dose

\begin{tabular}{|c|c|c|c|c|c|c|}
\hline \multirow{2}{*}{$\begin{array}{l}\text { Group } \\
\text { No }\end{array}$} & \multirow[b]{2}{*}{ Group } & \multirow[b]{2}{*}{$\begin{array}{c}\text { Dose } \\
\text { (cells/kg) }\end{array}$} & \multirow[b]{2}{*}{$\begin{array}{l}\text { Concentration } \\
\text { (cells } / \mathrm{mL})\end{array}$} & \multirow{2}{*}{$\begin{array}{l}\text { According to kilograms of } \\
\text { body weight equivalent to the } \\
\text { clinical dose required times }\end{array}$} & \multicolumn{2}{|c|}{ Animal number } \\
\hline & & & & & Female & Male \\
\hline 1 & $\begin{array}{l}\text { Control } \\
\text { group }\end{array}$ & 0 & 0 & - & $\begin{array}{c}13- \\
921 \sim 13- \\
923\end{array}$ & $\begin{array}{c}13- \\
924 \sim 13- \\
926\end{array}$ \\
\hline 2 & $\begin{array}{l}\text { low-dose } \\
\text { group }\end{array}$ & $2 \times 10^{6}$ & $2 \times 10^{5}$ & 2 & $\begin{array}{c}13- \\
927 \sim 13- \\
929\end{array}$ & $\begin{array}{c}13- \\
930 \sim 13- \\
932\end{array}$ \\
\hline 3 & $\begin{array}{l}\text { high-dose } \\
\text { group }\end{array}$ & $1 \times 10^{7}$ & $1 \times 10^{6}$ & 10 & $\begin{array}{c}13- \\
933 \sim 13- \\
935 \\
\end{array}$ & $\begin{array}{c}13- \\
936 \sim 13- \\
938 \\
\end{array}$ \\
\hline
\end{tabular}

Furthermore, these 18 monkeys were divided into three groups: group $1(n=6$, Female=3, Male=3, Control group), group 2 ( $n=6$, Female=3, Male=3, Low dose group) and group 3 ( $n=6$, Female=3, Male=3, High dose group). Infusion was performed according to Table 1 . Since the clinical use of stem cell therapy is usually the dose is $1 \times 10^{6}$ cells/ kilograms of body weight. The groups 2 transplant $2 \times 10^{6}$ cells/ kilograms of body weight, the dose are 2 times the clinical dose. The groups 3 transplant $1 \times 10^{7}$ cells / kilograms of body weight, the dose are 10 times the clinical dose.

Preparation and infusion of experimental reagents in each group. Preparation of the negative reference substance: An injection of $0.9 \%$ sodium chloride was given with no preparation. Infusion was performed for monkeys in the group 1.

Preparation of the Formulation A solution: A solution containing 1\% human serum albumin was prepared with Compound Electrolyte Injection. Formulation A solution can prevent cell aggregation, ensure single cell suspension.

Cells (mUC-MSCs) were removed from liquid nitrogen and rapidly placed in a water bath at $40^{\circ} \mathrm{C}$. During this period, the cryopreserved tubes were continuously shaken, and the cell suspension was allowed to rapidly melt. After the cell suspension completely melted, the frozen tubes are removed from the water bath and were run aseptically in a clean bench to complete the dilution process.

First, the outer surface of the cell tubes were wiped using cotton balls with alcohol, a small amount of cell suspension was taken, and cells were diluted with the appropriate amount of A solution after suspension with trypan blue staining to determine cell viability and count. When the activity rate reached $80 \%-100 \%$, these cells were used for the study. Otherwise, these cells were discarded. The mUC-MSCs in the frozen tubes were transferred into a sterile tube, and an appropriate amount of Formulation A was added. Cells were centrifuged at $330 \mathrm{~g}$ for five minutes, the supernatant was discarded, and cells were resuspended with the appropriate amount of Formulation A. Then, cells were counted and cell viability was measured. When viability was within the range of $80 \%-100 \%$, these cells were used for the study. Otherwise, these cells were discarded. Cell concentration was adjusted to $1 \times 10^{6}$ cells $/ \mathrm{mL}$, using the solution adjusted to $2 \times 10^{5}$ cells $/ \mathrm{mL}$ to reach a final concentration of $1 \%$ human serum albumin, and adjusted to $1,050 \mathrm{IU} / 4 \times 10^{7}$ cells using low molecular weight heparin calcium. The purpose of the addition of $1 \%$ human serum albumin, and low molecular weight heparin calcium is to maintain cell activity, to avoid cell aggregation, so that cells scattered into a single cell, is conducive to cell transplantation. Then, cells were counted again when the activity rate was within the $80 \%-100 \%$ range. Concentrations of the theoretical concentration of $80 \%$ $120 \%$ were used. When the activity was satisfied and the concentration was out of range, the concentration was readjusted. Concentrations within $80 \%-120 \%$ of the theoretical concentration were used, placed in an ice box for transport, and intravenous infusion was performed within four hours after preparation. Infusion was performed once every 14 days for 98 days, for a total of eight sessions.

Main monitoring indicators. The main test indicators after infusion: (1) body weight, (2) electrocardiogram, (3) hematology indicators, (4) blood biochemistry, and (5) immunological indicators (the day before the first infusion (D-1), the next day following the first infusion(D1), the next day following the third infusion(D42), the next day following the fifth infusion(D70), the next day following the last infusion(D84), and the end of the D126. Cell count was detected in blood collected through the hind limb subcutaneous vein. Then, a coagulation test was performed, hemo-lymphocyte subsets were detected (the percentage of $\mathrm{CD}^{+}, \mathrm{CD}^{+}$and $\mathrm{CD}^{+}$in peripheral blood was measured; and the $\mathrm{CD}^{+} / \mathrm{CD}^{+}$ratio was calculated), cytokine test was performed (IL-10, IL-4, IL-5, IL-6, IFN- $\gamma$ and TNF- $\alpha$ ), and immunoglobulin detection was conducted (serum IgG content). At the last infusion (D99) and after the end of the D126, a blood T-lymphocyte proliferation test was performed (MTS one step). 


\section{Cellular Physiology Cell Physiol Biochem 2017;43:891-904 \begin{tabular}{l|l|l|}
\hline DOI: 10.1159/000481639 & $\begin{array}{l}\text { C) } 2017 \text { The Author(s). Published by S. Karger AG, Basel } \\
\text { www.karger.com/cpb }\end{array}$
\end{tabular}}

He et al.: Chronic Toxicity Test of Muc-Mscs

Pharmacokinetics, tissue distribution and colonization differentiation. Blood collection time and animals: first infusion (D1), all animals in groups 2 and 3; eighth infusion, 15 and 30 minutes after infusion, all female animals in groups 2 and 3, respectively, immediately underwent infusion treatment for 1, 2, 4, 8 and 24 hours (immediate infusion, 15 and 30 minutes after infusion, blood in \pm 1 minute to complete; $1,2,4$, 8 and 24 hours, blood in \pm 5 minutes to complete). Blood samples were used for toxicokinetic studies (male animals were not tested at the first infusion). After infusion treatment for animals in group 3 , the animals were allowed to recover 28 days, 56 days, and 84 days. Blood was collected from two female monkeys before euthanasia for tissue distribution studies.

Blood sampling method: A 1-mL syringe was used to collect approximately $1 \mathrm{~mL}$ of blood via the subcutaneous vein of the monkey. The collected blood was placed into $250-\mu \mathrm{L} /$ tubes, kept on ice in temporary storage, and transferred to a refrigerator at $-70^{\circ} \mathrm{C}$ for analysis.

Animal collection time: In the study, 2 and 3 groups of animals, and the euthanized female animals were used for the tissue distribution and colonization differentiation study. Two female animals (animal no. 13-921 and 13-922) in group 1 were collected at the end of the infusion after euthanasia.

Detection method: Toxicity and intracellular distribution were detected by Q-PCR. Plasmid DNA pMD19-SRY2, a specific fragment of the sex-determining gene SRY on the chromosome of male cynomolgus monkeys, was studied. Male-derived mUC-MSC total DNA was distributed in female cynomolgus monkeys by quantitative PCR. This allowed the indirect determination of the metabolism and distribution of mUC-MSCs in female animals. This method was specific for the SRY2 sequence on the genomic DNA of cynomolgus monkeys. The standard plasmid pMD19-SRY2 was within the range of 102-107 copies/reaction/0.5 $\mu \mathrm{g}$ of the total DNA, and LOD and LOQ are at 100 copies/reaction/0.5 $\mu \mathrm{g}$ total DNA. Due to the mUC-MSCs were not distributed in all tissues, and the distribution of mUC-MSCs was not studied.

Observation of euthanasia and the recovery period. Two days after the last infusion, euthanasia was implemented in two animals (one male and one female) in each group. The animals were observed and the euthanasia was planned, in order to understand the recovery of toxic reactions and possible delayed toxicity. At the end of the observation period, ketamine was intramuscularly injected with ketamine at a dose of 10 $\mathrm{mg} / \mathrm{kg}$. After the animals became silent, the animals were anesthetized with an intravenous injection of $20 \mathrm{mg} / \mathrm{kg}$ of pentobarbital sodium until the animals entered an unconscious state. Femoral artery rapid bloodletting was performed and euthanasia was conducted on the animals.

Data processing methods. Statistical analysis: Body weight, body temperature, electrocardiogram, blood cell count, coagulation index, the blood biochemical index, T lymphocyte subsets, IgG, cytokines and other indexes in each group were statistically analyzed according to the following methods. Results were expressed as mean \pm standard deviation (SD), and statistical level was set at 0.05 . The difference between the group 2, 3 and group 1 was compared. Results were simultaneously analyzed with statistical significance and biological significance. When analyzing the biological significance of the data, changes before and after the infusion were also analyzed. The specific analysis method was as follows.

The variance was evaluated using Levene's Test. If there was no statistical significance $(P>0.05)$, singlefactor analysis of variance (ANOVA) was used for statistical analysis. If ANOVA has statistically significant $(P \leq 0.05)$, Dunnett's Test (parameter method) was used for comparative analysis.

\section{Results}

\section{Morphological observation of mUC-MSCS}

The mUC-MSCs were cultured without peeling off the blood vessels and capsule tissues. At the first five days after inverted-phase contrast microscopy, few spindle-adherent cells or cells grown from adherent tissue blocks were observed (Fig. 1A). At nine days, a large number of spindle cells transformed into large clonal growths (Fig. 1B), and primary cell digestion and passage were performed. When the cell was evenly distributed to $80 \%-90 \%$ fusion, it was observed that a large number of reticular-shaped fibroblast-like cells swirled, presented a radial growth, and had morphological characteristics similar to human UC-MSCs (Fig. 1C). 


\section{Cellular Physiology \begin{tabular}{ll|l} 
and Biochemistry & Published online: September 29, 2017 & $\begin{array}{l}\text { (c) } 2017 \text { The Author(s). Published by S. Karger AG, Basel } \\
\text { www.karger.com/cpb }\end{array}$
\end{tabular}

Immunophenotype of mUC-MSCS

The third generation of mUC-MSCs with stable growth was detected by flow cytometry. Flow cytometry results are shown in Table 2 and Fig. 2. It showed CD29 、CD90、CD44 positive rate were $100 \%$, CD34 positive rate was $0.1 \%$, CD45 positive rate was $0.7 \%$. The expression of cell surface markers is consistent with the characteristics of umbilical cord mesenchymal stem cells.

\section{Proliferation ability of $\mathrm{mUC}-\mathrm{MSCS}$}

In the growth curve (Fig. 3), it can be observed that cells were in the retention period at two days when inoculation and proliferation were not obvious. After 3-7 days into the logarithmic proliferation period, cell growth had the best activity. Cell growth at the eighth day presented a platform growth period. The growth curve of mUC-MSCs exhibited a typical "S" trend.

\section{Differentiation ability of mUC-MSCs}

Adipose differentiation: Cell adipogenic differentiation was induced after 14-21 days, oil red 0 staining was performed, and the cytoplasm was observed within the red fat droplets (Fig. 4A). Osteogenic differentiation: Induction was performed after 14-21 days, and calcium nodules were stained red by Alizarin red staining (Fig. 4B). Cartilage differentiation: Induction was performed after 14-28 days, the sections were paraffin embedded, and melanin in the cartilage collagen matrix was stained blue (Fig. 4C). We demonstrate that UC-MSC can differentiate to fat, bone and cartilage and are similar to BM-MSC, but differ from placentaderived fetal membrane so called decidual stromal cells.

\section{Chronic toxicity test}

Animal deaths. During the trial period, three groups did not incur animal deaths.

Weight. Compared with the group 1, the body weight of animals in the groups 2,3 was not statistically different $(P>0.05)$.

Body temperature. Compared with the group 1, the body temperature of animals in the groups 2, 3 had no significant difference $(P>0.05)$.

ECG. Compared with the group 1, the electrocardiogram results of animals in the groups 2, 3 had no significant difference $(P>0.05)$.

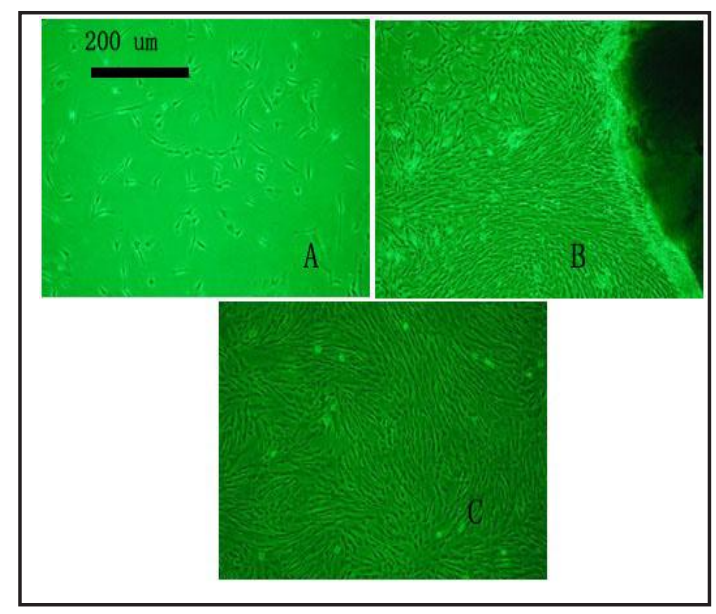

Fig. 1. Morphology of mUC-MSCs observed under an inverted phase-contrast microscope $(\times 100)$. (A) The umbilical cord tissue was adherent. During the first five days, a small number of sporadically scattered spindle cells around the tissues blocks are shown. (B) A large number of cells from the tissue block of the clonal growth are shown. (C) Cells were radial growth after the passage is shown.

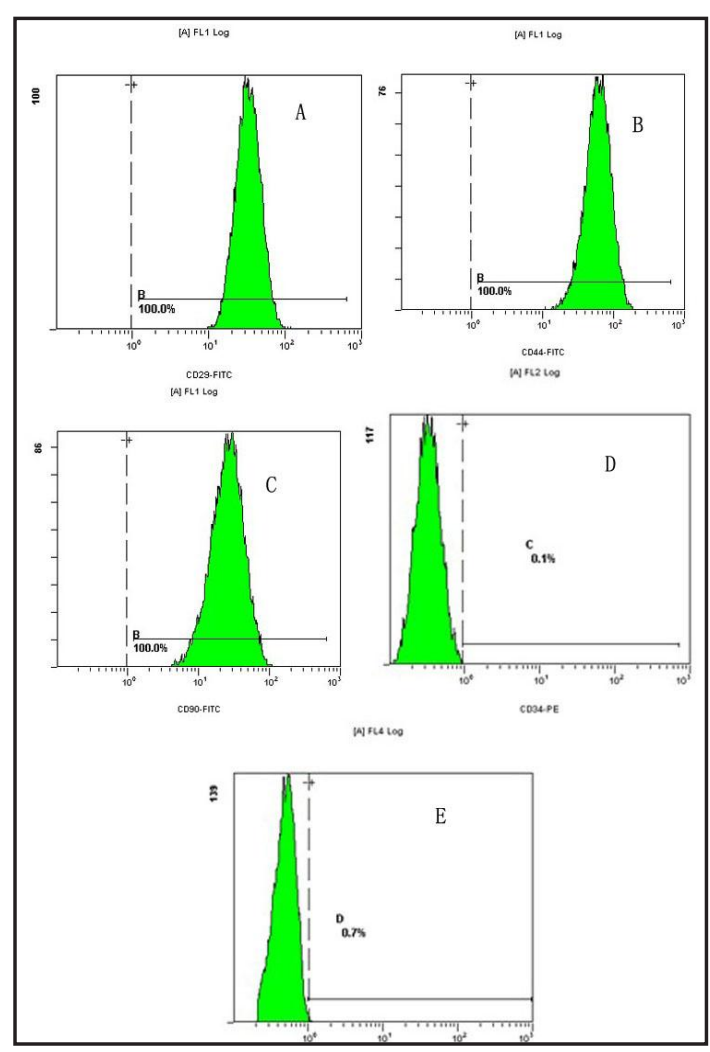

Fig. 2. Surface antigen marker results of mUCMSCs. It showed CD29、CD90、CD44 positive rate were $100 \%$, CD34 positive rate was $0.1 \%$, CD45 positive rate was $0.7 \%$. Expression consistent with umbilical cord mesenchymal stem cells. 
Hematological indicators. Compared with the same period for the group 1, the hematological indicators were statistically significant $(P \leq 0.05)$. Other hematological indicators (RBC, HGB, HCT, $\mathrm{MCV}, \mathrm{MCH}, \mathrm{MCHC}$, Mono, Eos, and Baso) were not statistically significant $(P>0.05)$.

In the groups 2, 3, Neut (\%) increased after the third infusion at day 30. After the last infusion at day 100 , Neut (\%) increased in the groups 2 (Fig. 5A).

Lymph (\%) decreased in the groups 2,3 on the next day after the third infusion (D 30), and lymph (\%) decreased in the groups 2 (D 100) after the last infusion (Fig. 5B).

In the group 3 , white blood cell (WBC) count decreased (D 58, Fig. 5C), Neut $\left(\times 10^{9} / \mathrm{L}\right)$ decreased (D 58, Fig. 5D), and lymph $\left(\times 10^{9} / \mathrm{L}\right)$ decreased (D 58, Fig. 5E). Lymph $\left(\times 10^{9} / \mathrm{L}\right)$ decreased in the group 3 (Fig. 5E) after the third instillation (D 30).

Compared with the control group and the pre-infusion value, changes in Neut, Lymph and WBC in the above indexes fluctuated within the normal range of the laboratory, and there were no obvious regularities. Furthermore, there was no dose-response or time-response correlation, and there was non-toxicological significance.

Coagulation index. Compared with the group 1, the coagulation indexes of the animals in the groups 2, 3 were not statistically different $(P>0.05)$.

Blood biochemical index. Compared with the same period for the group 1, the following hematological indicators were statistically significant $(P \leq 0.05)$.

At the second day after the first infusion (D2), AST increased in the groups 2, 3 (Fig. 6A). Elevated AST may be due to early homing of MSCs to the liver.

Cytokines (CK) in the groups 2, 3 were higher on the next day after the first infusion (D2, Fig. 6B).

On the next day after the third infusion (D 30) and the next day after the fifth infusion (D 58), P decreased in the group 3; and on the next day of the last infusion (D 100), P was lower in the groups 2, 3 (Fig. 6C).
Table 2. Flow cytomstry detection of mUC-MSC surface antigen marker results $(\mathrm{n}=5)$

\begin{tabular}{lccccc}
\hline & CD29-FITC & CD44-FITC & CD90-FITC & CD34-PE & CD45-PC5 \\
\hline mUC-MSCs & $98 \pm 2 \%$ & $99 \pm 1 \%$ & $97 \pm 3 \%$ & $0.3 \pm 0.1 \%$ & $0.7 \pm 0.2 \%$ \\
\hline
\end{tabular}

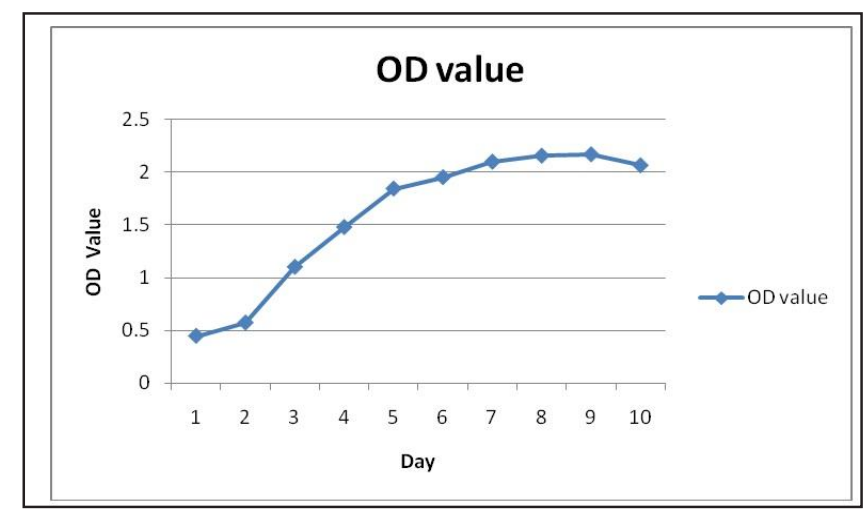

Fig. 3. Growth curve of mUC-MSCs (results are expressed as the mean, $n=10$ ). Cell growth at the eighth day presented a platform growth period. The growth curve of mUC-MSCs exhibited a typical "S" trend.

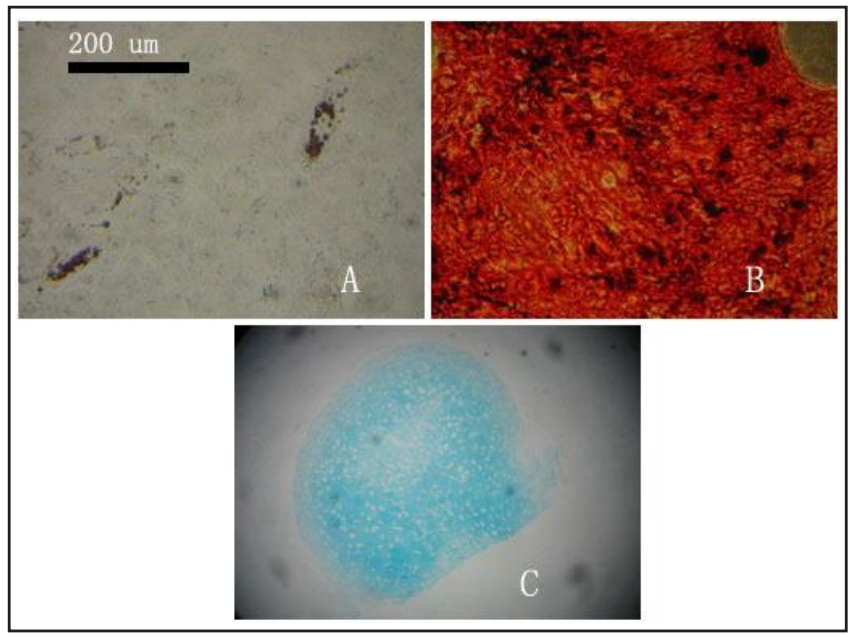

Fig. 4. Differentiation ability of mUC-MSCs. (A) Adipogenic differentiation: the cytoplasm can be observed within the red fat droplet. (B) Osteogenic differentiation: calcinosis nodules were stained red by alizarin red staining. (C) Cartilage differentiation: melanin was stained blue in the chondrocyte collagen matrix. 


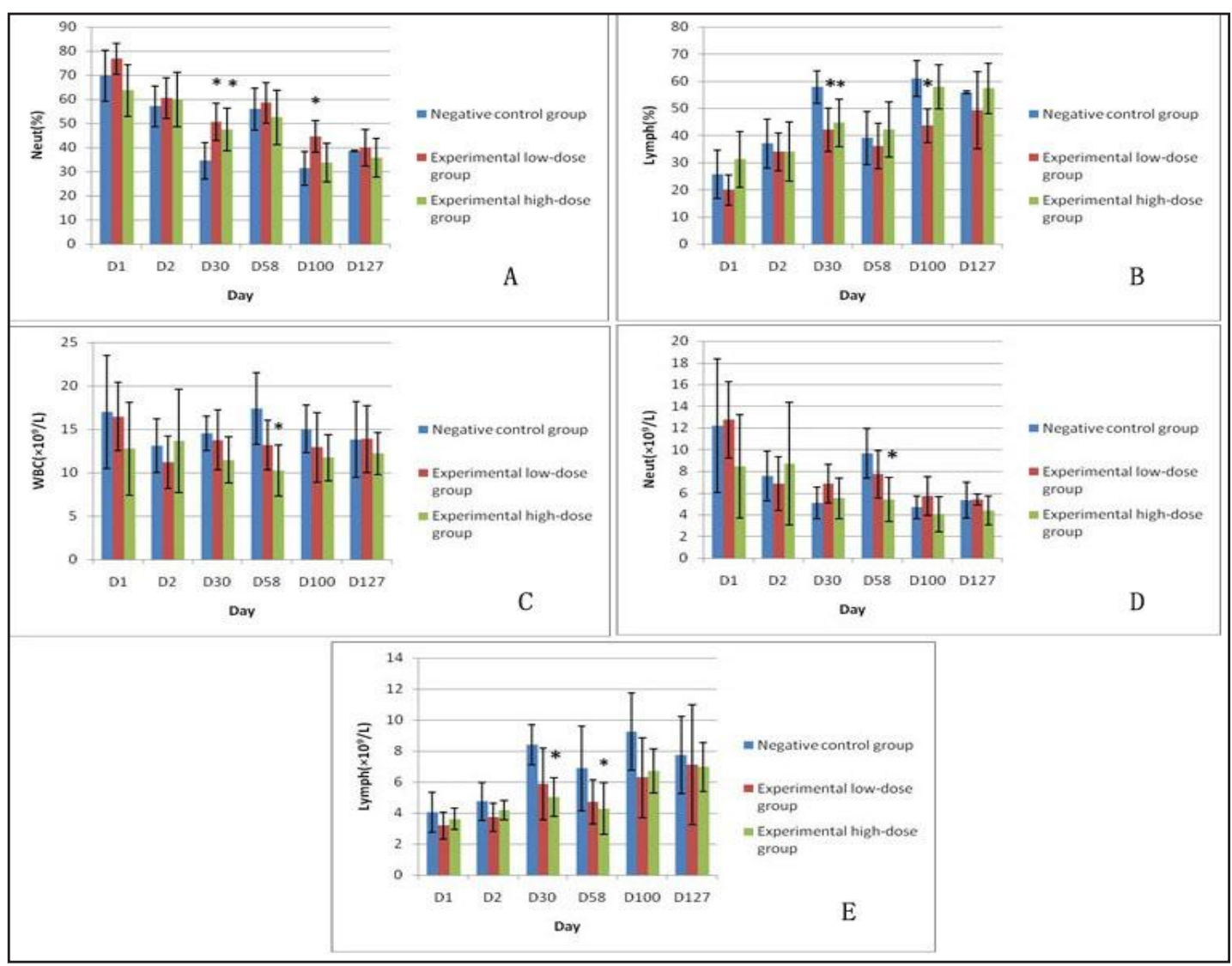

Fig. 5. Changes in hematological indicators. (A) Neut (\%) changes after repeated intravenous infusion of mUC-MSCs in cynomolgus monkeys for 98 days. In the groups 2, 3, Neut (\%) increased after the third infusion at day 30. After the last infusion at day 100, Neut (\%) increased in the groups 2.(B) Lymph (\%) changes after repeated intravenous infusion of mUC-MSCs in cynomolgus monkeys for 98 days. Lymph (\%) decreased in the groups 2, 3 on the next day after the third infusion (D 30), and lymph (\%) decreased in the groups 2 (D 100) after the last infusion(C) WBC changes after repeated venous infusion of mUC-MSCs in cynomolgus monkeys for 98 days. In the group 3, white blood cell (WBC) count decreased.(D) Neut $\left(\times 10^{9} / \mathrm{L}\right)$ changes after repeated venous infusion of mUC-MSCs in cynomolgus monkeys for 98 days. In the group 3, Neut $\left(\times 10^{9} / \mathrm{L}\right)$ decreased(E) Changes in lymph $\left(\times 10^{9} / \mathrm{L}\right)$ after repeated intravenous infusion of mUC-MSCs in cynomolgus monkeys for 98 days. In the group 3, lymph $\left(\times 10^{9} / \mathrm{L}\right)$ decreased (D 58). Lymph $\left(\times 10^{9} / \mathrm{L}\right)$ also decreased in the group 3 after the third instillation (D 30).*Indicates that compared with the same period for the group $1, \mathrm{P} \leq 0.05$.

AST in the group 3 was significantly higher than that in the group 2. After continuous infusion, AST was maintained at a high level in the groups 2, 3. After 28 days of transfusion, AST returned to the infusion level. This change may be related to the infusion of cells.

For the serum, inorganic $\mathrm{P}$ was significantly lower in the group 3 after the third infusion (D 30); and this significantly decreased in the group 2 after the last infusion (D 100). In the cell infusion processes, there was a certain dose-response and time-response correlation. After 28 days, cell infusion was stopped, and the levels returned to pre-infusion levels. Hence, these changes were related to the infusion of cells.

Other statistically significant differences fluctuated within the normal range in the laboratory, and there was no dose-response or time-response correlation. Hence, the difference was not toxicologically significant. 28 days after the end of the recovery period, no obvious abnormalities were found in the indexes of each group. 


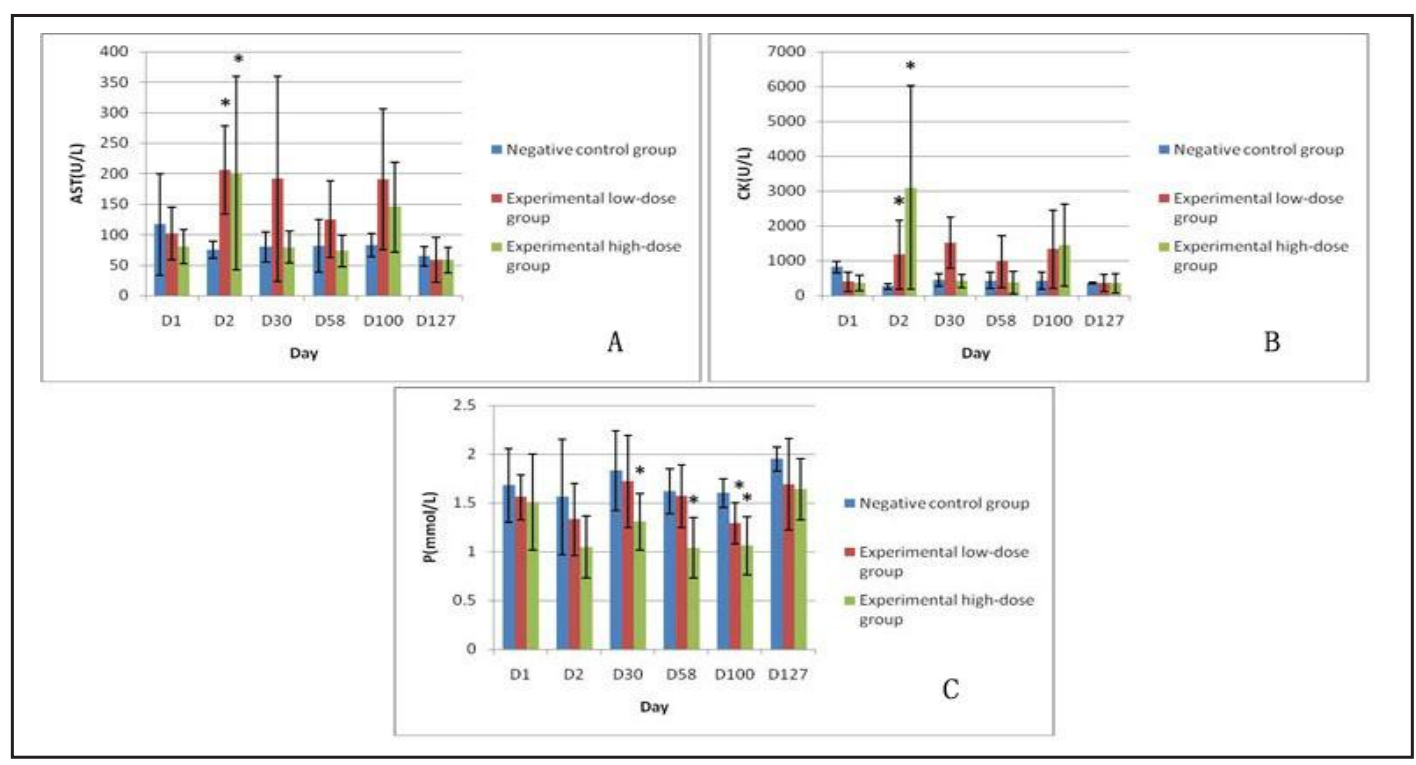

Fig. 6. Changes in the blood biochemical index. (A) AST changes after repeated venous infusions of mUCMSCs in cynomolgus monkeys for 98 days. At the second day after the first infusion (D2), AST increased in the groups 2, 3.(B) Changes in CK after repeated intravenous infusions of mUC-MSCs in cynomolgus monkeys for 98 days. Cytokines (CK) in the groups 2, 3 were higher on the next day after the first infusion (D2).(C) P changes after repeated intravenous infusions of mUC-MSCs in cynomolgus monkeys for 98 days. On the next day after the third infusion (D 30) and the next day after the fifth infusion (D 58), P decreased in the group 3; and on the next day of the last infusion (D 100), P was lower in the groups 2, 3*Indicates that compared with the same period for the group $1, \mathrm{P} \leq 0.05$.

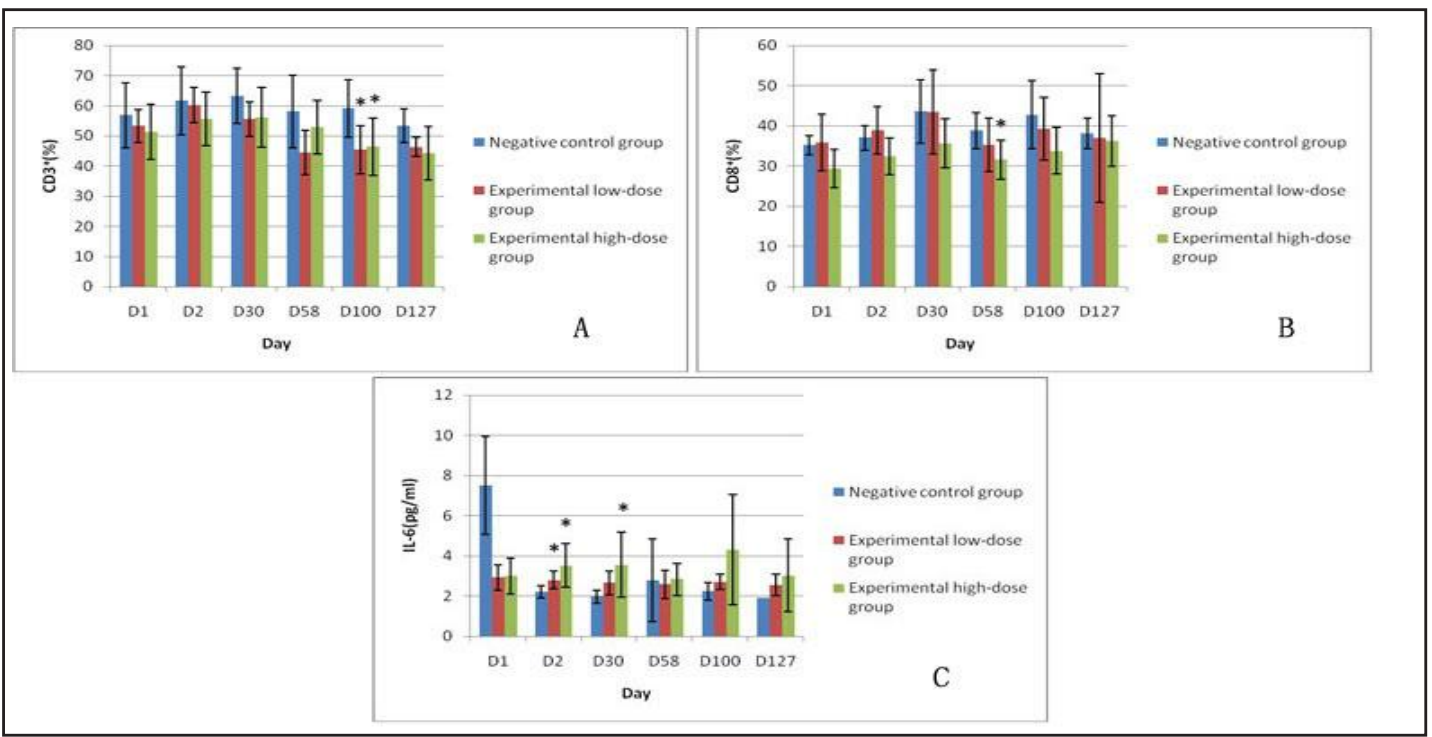

Fig. 7. Changes in immunological indicators. (A) Changes in the percentage of $\mathrm{CD}^{+}$cells after 98 days of repeated intravenous infusions of mUC-MSCs in cynomolgus monkeys. Compared with the group 1, the percentage of $\mathrm{CD}^{+}$cells in the groups 2,3 decreased $(\mathrm{P} \leq 0.05)$ after the last infusion (D 100).(B) Changes in the percentage of $\mathrm{CD}^{+}$cells after 98 days of repeated intravenous infusions of mUC-MSCs in cynomolgus monkeys. On the next day after the fifth infusion (D 58), $\mathrm{CD}^{+}$cells in the group 3 decreased $(\mathrm{P} \leq 0.05)$.(C) Changes in IL-6 levels after 98 days of repeated intravenous infusions of mUC-MSCs in cynomolgus monkeys.

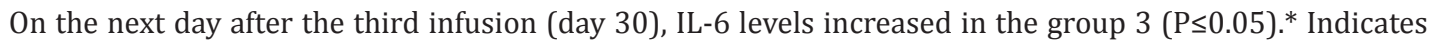
that compared with the same period for group $1, \mathrm{P} \leq 0.05$.

\section{KARGER}




\section{Cellular Physiology

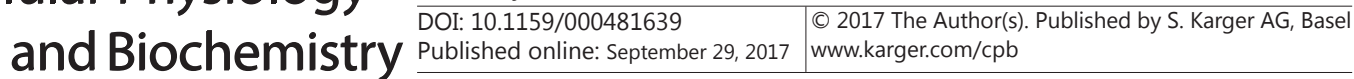

Fig. 8. Part of the pathology of the organizational structure. (A) Group 1 13-925 animals, repeated intravenous infusion for 98 days, the infusion of euthanasia, no significant abnormal changes were found in brain tissues, H\&E staining $(\times 10)$.(B) Group 3 13-937 animals, repeated intravenous infusion for 98 days, end of euthanasia infusion, brain tissues had no significant abnormal changes, and H\&E staining $(\times 10)$. (C) Group 1 13-925 animals, repeated intravenous infusion for 98 days, infusion of euthanasia, heart tissues had no significant abnormal changes, and H\&E staining (×10).(D) Group 3 13-937 animals, repeated intravenous infusion for 98 days, infusion end of euthanasia, heart tissues had no significant abnormal changes, and H\&E staining $(\times 10)$. (E) Group 1 13-925 animals, repeated intravenous infusion for 98 days, infusion end of euthanasia, liver tissues had no significant abnormal changes, and H\&E staining $(\times 10)$.(F) Group 3 13-937 animals, repeated intravenous infusion for 98 days, the end of the euthanasia infusion, liver tissues had no significant abnormal changes, and H\&E staining $(\times 10)$. $(G)$ Group 1 13-925 animals, repeated intravenous infusion for 98 days, the end of euthanasia, spleen tissues had no significant abnormal changes, and H\&E staining $(\times 10) .(\mathrm{H})$

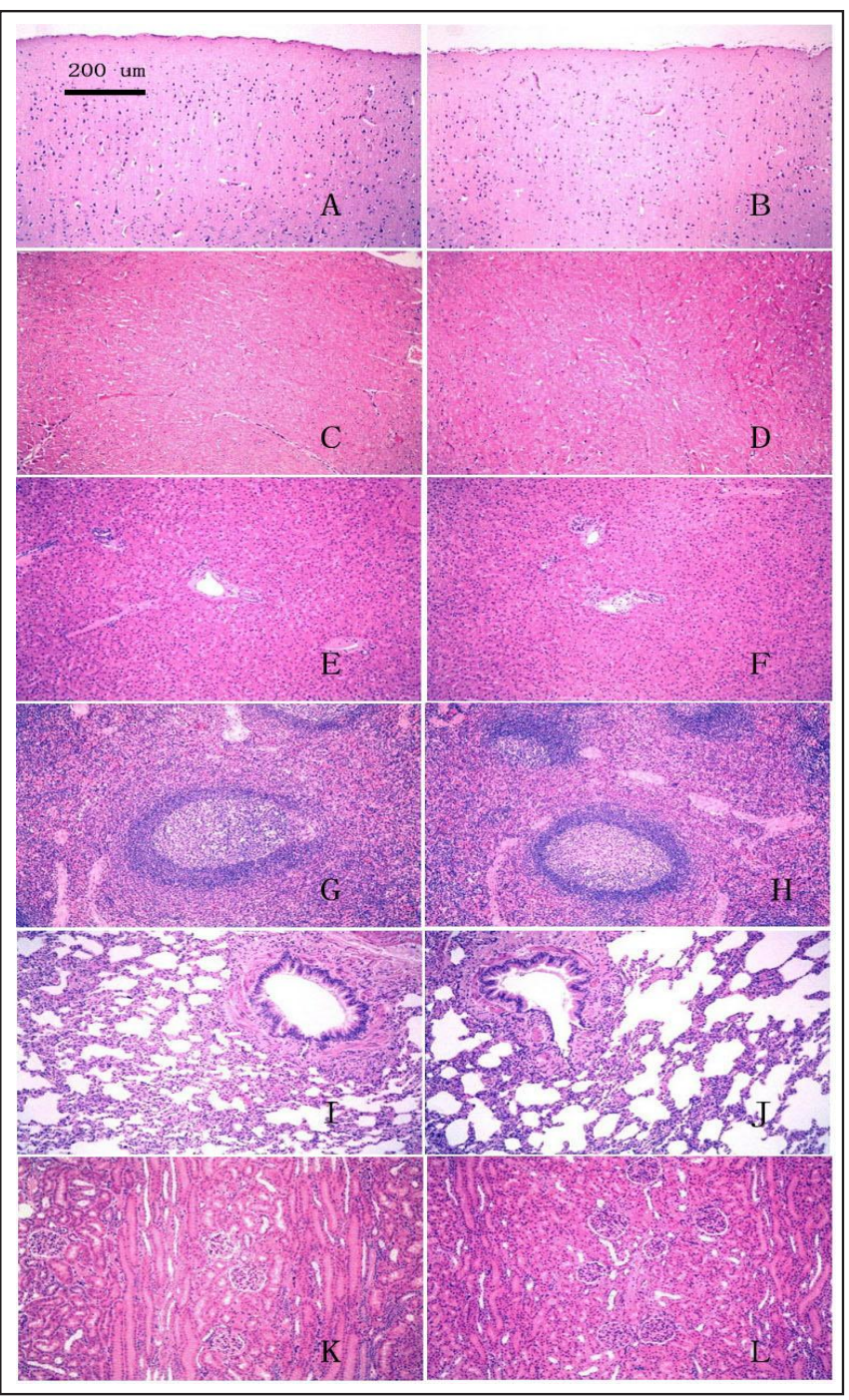
Group 3 13-937 animals, repeated intravenous infusion for 98 days, infusion end of euthanasia, spleen tissues had no significant abnormal changes, and H\&E staining $(\times 10)$.(I) Group 1 13-925 animals, repeated intravenous infusion for 98 days, infusion of euthanasia, lung tissues had no significant abnormal changes, and H\&E staining $(\times 10)$.(J) Group 313-937 animals, repeated intravenous infusion for 98 days, infusion end of euthanasia, lung tissues had no significant abnormal changes, and H\&E staining $(\times 10) .(\mathrm{K})$ Group 1 13-925 animals, repeated intravenous infusion for 98 days, infusion end of euthanasia, no obvious abnormal changes occurred in renal tissues, and H\&E staining $(\times 10)$.(L) Group 3 13-937 animals, repeated intravenous infusion for 98 days, infusion end of euthanasia, kidney tissues had no significant abnormal changes, and H\&E staining $(\times 10)$.

\section{Immunological indicators}

Distribution of T lymphocyte subsets. Compared with the group 1, the percentage of CD3 ${ }^{+}$ cells in the groups 2,3 decreased ( $P \leq 0.05$, Fig. 7A) after the last infusion (D 100). On the next day after the fifth infusion (D 58), $\mathrm{CD} 8^{+}$cells in the group 3 decreased ( $P \leq 0.05$, Fig. 7B). The other indicators were not statistically significant $(P>0.05)$.

$T$ lymphocyte proliferation test. Compared with the group 1, there was no significant difference in $\mathrm{T}$ lymphocyte proliferation in each group $(P>0.05)$. 


\section{Cellular Physiology Cell Physiol Biochem 2017;43:891-904 \begin{tabular}{ll|l} 
and Biochemistry Published online: September 29, 2017 & $\begin{array}{l}\text { (c) } 2017 \text { The Author(s). Published by S. Karger AG, Basel } \\
\text { www.karger.com/cpb }\end{array}$ \\
\hline
\end{tabular}

Cytokines. On next day after the first infusion, IL-6 levels in the groups 2, 3 were significantly higher than that in the group $1(P \leq 0.05)$. On the next day after the third infusion (day 30), IL-6 levels increased in the group 3 ( $P \leq 0.05$, Fig. $7 \mathrm{C})$. There were no significant differences in cytokine level among the other time points $(P>0.05)$.

Immunoglobulin. Compared with the group 1, the immunoglobulin IgG values of the animals in the groups 2, 3 were not statistically different $(P>0.05)$.

Metabolic kinetics, tissue distribution and colonization differentiation. Plasmid DNA pMD19-SRY2, which is a specific fragment of the sex-determining gene SRY in the male cynomolgus monkey $\mathrm{Y}$ chromosome was used for this study, and the quantitative PCR method was used to determine the total DNA of mUC-MSCs derived from male origin to observe the distribution in female cynomolgus monkeys. Hence, this would indirectly determine the metabolism and distribution of mUC-MSCs in female animals.

For the preparation of mUC-MSC for cynomolgus monkeys at doses of $2 \times 10^{6} / \mathrm{kg}$ and $1 \times 10^{7} / \mathrm{kg}$, the plasma concentration of the animals increased as the dosage increased during the first infusion. Infusion was performed once every 14 days, for eight times. At 24 hours after infusion, blood concentration in the body of these animals increased, which was higher than that during the initial infusion.

The ratios of $\mathrm{C}_{\max }$ and $\mathrm{AUC}_{0-24 \mathrm{~h}}$ were $1: 4.20$ and 1:1.44, respectively; and the ratio of $\mathrm{C}_{\max }$ and $\mathrm{AUC}_{0-24 \mathrm{~h}}$ after the last infusion was 1:2.20 and 1:1.41, respectively.

The kinetic parameters of the preparation of mUC-MSC for the animals are shown in Table 3.

At a range between $2 \times 10^{6} / \mathrm{kg}$ and $1 \times 10^{7} / \mathrm{kg}$, the $\mathrm{C}_{\max }$ of the group 3 after the last infusion was lower than that of the first infusion $(P=0.022)$, and $\mathrm{AUC}_{0-24 \mathrm{~h}}$ was had no significant difference $(P>0.05)$ compared with the first infusion. There was no significant difference in $\mathrm{C}_{\max }$ and $\mathrm{AUC}_{0-24 \mathrm{~h}}$ in the group $2(P>0.05)$ at first infusion, compared with last infusion. Infusion was performed once every 14 days, for eight times; and the accumulation factor for the groups 2, 3 was 1.48 and 2.23, respectively.

The genomic DNA content of male cynomolgus monkeys in each female group was lower than the lower limit of quantification, and no tissue distribution was detected. Colonization differentiation was not carried out in this study.

\section{Pathological examination}

System autopsy. 28 days after the end of cell infusion and during the recovery period, no abnormal changes were observed in the animals in each group.

Histopathological examination. A total of 9 animals were euthanized at the end of the infusion treatment (D 100), and 9 animals were euthanized at the end of the recovery period (D 127). There were no obvious pathological changes associated with the infusion of cells in the general and microscopic examinations. No related irritations occurred in local blood vessels injected with infusion cells. Part of the histopathology report is shown in Fig. 8.

\section{Discussion}

hUC-MSCs may be an alternative source of stem cells and are worthy of study in longterm clinical trials. MSCs are a promising therapeutic resource. Paracrine effects and 
theinduction of differentiation patterns are thought to represent the two primary mechanisms underlying the therapeutic effects of MSC transplantation in vivo. However, it is unclear which mechanism is involved in the therapeutic effects of hUC-MSC transplantation [14]. hUC-MSCs ameliorate dextran sulfate sodium (DSS)-induced colitis via the downregulation of colon inflammatory responses [15]. Furthermore, hUC-MSCs adjusted modulation of Treg/ Th17 cells in the spleen and mesenteric lymph nodes. hUC-MSCs also inhibited lamina propria mononuclear cells (LPMCs) in vitro [15]. Zhang et al. [16]. reported UC-MSCs suppressed umbilical cord blood lymphocyte proliferation stimulated by mitogen, and ELISA showed that the secretion of INF- $\gamma$ was downregulated, and the secretion of IL- 4 was upregulated, with CD8+ T cells markedly decreased and CD4+ T cells changed lightly. Moreover, the infusion of UC-MSCs in recipient mice transplanted with donor bone marrow cells ameliorated acute graft-versus host disease (aGVHD) and extended survival. In conclusion, UC-MSCs might negatively modulate immunoreactions, and have application potential in the treatment of a GVHD caused by allogeneic stem cells transplantation. mUC-MSCs from monkeys were used for this experiment to imitate hUC-MSCs used for human. Van et al. [17]. analysized pluripotent cell markers showed UC-MSCs maintained the expression of the oncogenes Nanog and Oct4 after long term culture but failed to transfer tumors in NOD/SCID mice. Umbilical cord (UC) is a rich source of rapidly proliferating mesenchymal stem cells (MSCs) that are easily cultured on a large-scale. Clinical applications of UC-MSCs include graftversus-host disease, and diabetes mellitus types 1 and 2. UC-MSCs should be isolated and proliferated according to good manufacturing practice (GMP) with animal component-free medium, quality assurance, and quality control for their use in clinical applications. They are attractive autologous or allogenic agents for the treatment of malignant and nonmalignant solid and soft cancers. hUC-MSCs also can be the feeder layer for embryonic stem cells or other pluripotent stem cells. Regarding their therapeutic value, storage banking system and protocols should be established immediately. Ding et al. [18]. critically evaluates their therapeutic value, challenges, and future directions for their clinical applications.

The toxicity of stem cell preparations is similar to that of general biological agents, and overall toxicity tests needs to simulate the clinical infusion regimen as much as possible. The dose used should be simulated as much as possible. The information obtained in the toxicity test can help guide the design of clinical trials. If it is difficult to use relevant animals to evaluate the toxicity of human stem cells, the possibility of simulating clinical applications should be considered as much as possible using animal stem cells that correspond to the source, and to those higher than the clinical application of the dose of animals, in order to observe the toxicity in the body. Considering that cynomolgus monkeys are non-human primates, and has the closest genetic relationship to humans, mUC-MSCs have been established. Wang et al. [19]. designed a study to evaluate the overall toxicology of hUC-MSCs in cynomolgus monkeys with repeated administration. They found that the transplantation of hUC-MSCs did not affect the general health of cynomolgus monkeys. In this study, mUCMSCs were administered to cynomolgus monkeys several times, in order to evaluate the safety of the allogeneic infusion of mUC-MSCs and their effects on the immune system, in order to obtain more reliable chronic toxicological data. Therapies based on stem cells have shown very attractive potential in many clinical studies. However, the data about the safety of stem cells application remains insufficient.

In the course of the experiment, the infusion of cells once every 14 days for 98 days did not reveal any abnormal symptoms associated with the infusion cells; and weight did not reveal any significant reduction. General pharmacological indicators such as ECG and body temperature did not reveal any abnormality, suggesting that the infusion of mUC-MSCs in cynomolgus monkeys did not induce any obvious general symptom. In blood biochemical indexes, AST and CK were higher in the groups 2, 3 on the next day after the first infusion (D 2), this significantly increased in individual animals, and these were reduced to preinfusion levels in other time points. In summary, AST and CK are related to liver function, but states may exhibit a significant abnormal increase in external environment changes or stress, although the changes in this study were transient. Animals in the group 1 did not 
present any abnormal changes. Hence, it was considered that the fluctuation of this indicator may be related to the infusion of cells. In summary, the allogeneic infusion of mUC-MSCs was performed for 98 days in cynomolgus monkeys. There was no abnormal change in the presence of toxic reactions in the animals, indicating the safety of this treatment. In the future we can use hUC-MSCs to treat human diseases, confirmed by animal experiments is safe and effective.

The distribution of $\mathrm{T}$ lymphocyte subsets in peripheral blood was examined in this study, in which $\mathrm{CD}^{+}$cells were reduced on the next day (D 100) after the last infusion. A literature confirmed that MSCs have immunomodulatory abilities [20], and can affect various $\mathrm{T}$ cell functions. Most importantly, it inhibits the activation of CD4 ${ }^{+}$Th cells and CD8 ${ }^{+}$CTL proliferation and inhibits $\mathrm{CD}^{+}$CTL cytotoxicity, while UC-MSCs inhibits the activation of T cells in the cell G0/G1 phase without causing T cell apoptosis. The results of this experiment revealed that in the allogeneic infusion of mUC-MSCs in cynomolgus monkeys, $\mathrm{CD}^{+}$cells decreased probably due to the secretion of inhibitory cytokines of mUC-MSCs and the inhibition of the proliferation of T cells.

For IFN- $\gamma$, IL-4, IL-5, IL-6, IL-10, TNF-a and other cytokines, only IL-6 significantly increased; and this was reduced to the infusion pre-level at the end of the recovery period. IL-6 is a cytokine produced by activated T cells and fibroblasts, which can transform precursor B cells into antibody-producing plasma cells. On the other hand, with the colonystimulating factor, it can promote bone marrow primitive cell growth and differentiation, and enhance natural killer cell lysis function. IL-6 is secreted by UC-MSCs [21]. It mainly acts on the transformation of monocytes to dendritic cells, reduces the antigen presentation of $\mathrm{T}$ cells on DC cells, and inhibits T cell activation. The increase in IL-6 in this experiment may be due to the introduction of exogenous mUC-MSCs, which may be proportional to the duration of mUC-MSC retention and function in vivo.

\section{Conclusion}

Stem cell-based therapy is attractive in many clinical studies, but current data on the safety of stem cell applications remains inadequate. This study aimed to observe the safety, immunological effect and distribution of mUC-MSCs injected into cynomolgus monkeys. mUC-MSCs from monkeys were used for this experiment to imitate hUC-MSCs used for human. In summary, mUC-MSCs did not show significant toxic effects after its administration in allogeneic cynomolgus monkeys, but did play an immunomodulatory role through the effects of T lymphocyte subsets and IL-6 secretion. The safe dosage of repeated intravenous infusion of mUC-MSCs in cynomolgus monkeys is $1.0 \times 10^{7} / \mathrm{kg}$, which is 10 times of that in clinical use.

\section{Abbreviations}

mUC-MSCs (Cynomolgus monkey umbilical cord mesenchymal stem cells); hUC-MSCs (human umbilical cord mesenchymal stem cells); GVHD (graft-versus-host disease); P3 (the third passage cells); ANOVA (analysis of variance).

\section{Acknowledgements}

We thank Medjaden Bioscience Limited for assisting in the preparation of this manuscript. This work was supported by the National Support Program (2014BAI01B01), the Yunnan Province Applied Basic Research Program Key Project ( 2017FA040) and the Yunnan Province Health Science and Technology Project (2016NS012).

\section{Disclosure Statement}

The authors declare that they have no competing interests. 


\section{Cellular Physiology Cell Physiol Biochem 2017;43:891-904

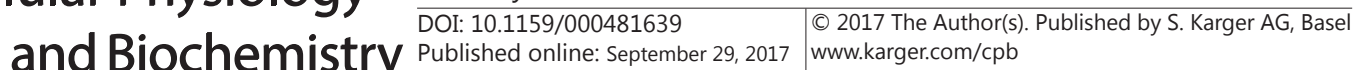

and Biochemistry $\frac{\text { Published online: September } 29,207}{\text { He et al.: Chronic Toxicity Test of Muc-Mscs }}$

\section{References}

1 Chamberlain G, Fox J, Ashton B, Middleton J: Concise review: mesenchymal stem cells: their phenotype, differentiation capacity, immunological features, and potential for homing. Stem Cells 2007;25:2739-2749.

-2 Mitchell KE, Weiss ML, Mitchell BM, Martin P, Davis D, Morales L, Helwig B, Beerenstrauch M, Abou-Easa $\mathrm{K}$, Hildreth T, Troyer D, Medicetty S: Matrix cells from Wharton's jelly form neurons and glia. Stem Cells 2003;21:50-60.

-3 Zhao L, Weir MD, Xu HH: An injectable calcium phosphate-alginate hydrogel-umbilical cord mesenchymal stem cell paste for bone tissue engineering. Biomaterials 2010;31:6502-6510.

$\checkmark 4$ Balci D, Can A: The assessment of cryopreservation conditions for human umbilical cord stroma-derived mesenchymal stem cells towards a potential use for stem cell banking. Curr Stem Cell Res Ther 2013;8:6072.

5 Hu L, Hu J, Zhao J, Liu J, Ouyang W, Yang C, Gong N, Du L, Khanal A, Chen L: Side-by-side comparison of the biological characteristics of human umbilical cord and adipose tissue-derived mesenchymal stem cells. Biomed Res Int 2013;2013:438243.

6 Kim SM, Moon SH, Lee Y, Kim GJ, Chung HM, Choi YS: Alternative xeno-free biomaterials derived from human umbilical cord for the self-renewal ex-vivo expansion of mesenchymal stem cells. Stem Cells Dev 2013;22:3025-3038.

7 Lonne M, Lavrentieva A, Walter JG, Kasper C: Analysis of oxygen-dependent cytokine expression in human mesenchymal stem cells derived from umbilical cord. Cell Tissue Res 2013;353:117-122.

8 MacDonald GI, Augello A, De Bari C: Role of mesenchymal stem cells in reestablishing immunologic tolerance in autoimmune rheumatic diseases. Arthritis Rheum 2011;63:2547-2557.

-9 Ringden 0, Le Blanc K: Mesenchymal stem cells for treatment of acute and chronic graft-versus-host disease, tissue toxicity and hemorrhages. Best Pract Res Clin Haematol 2011;24:65-72.

10 Wang W, Liu X, Li J, Li Y, Li L, Wang S, Zhang J, Zhang Y, Huang H: The Effects of Indoxyl Sulfate on Human Umbilical Cord-Derived Mesenchymal Stem Cells In vitro. Cell Physiol Biochem 2016;38:401-414.

-11 Bosse R, Singhofer-Wowra M, Rosenthal F, Schulz G: Good manufacturing practice production of human stem cells for somatic cell and gene therapy. Stem Cells 1997;15:S275-280.

12 Li T, Xia M, Gao Y, Chen Y, Xu Y: Human umbilical cord mesenchymal stem cells: an overview of their potential in cell-based therapy. Expert Opin Biol Ther 2015;15:1293-1306.

13 Taylor K: Clinical veterinarian's perspective of non-human primate (NHP) use in drug safety studies. J Immunotoxicol 2010;7:114-119.

14 Zhou X, Gu J, Gu Y, He M, Bi Y, Chen J, Li T: Human Umbilical Cord-Derived Mesenchymal Stem Cells Improve Learning and Memory Function in Hypoxic-Ischemic Brain-Damaged Rats via an IL-8-Mediated Secretion Mechanism Rather than Differentiation Pattern Induction. Cell Physiol Biochem 2015;35:2383-2401.

15 Li L, Liu S, Xu Y, Zhang A, Jiang J, Tan W, Xing J, Feng G, Liu H, Huo F, Tang Q Gu Z: Human umbilical cordderived mesenchymal stem cells downregulate inflammatory responses by shifting the Treg/Th17 profile in experimental colitis. Pharmacology 2013;92:257-264.

16 Zhang H, Tao Y, Liu H, Ren S, Zhang B, Chen H: Immunomodulatory function of whole human umbilical cord derived mesenchymal stem cells. Mol Immunol 2017;87:293-299.

-17 Van Pham P, Truong NC, Le PT, Tran TD, Vu NB, Bui KH, Phan NK: Isolation and proliferation of umbilical cord tissue derived mesenchymal stem cells for clinical applications. Cell Tissue Bank 2016;17:289-302.

$>18$ Ding DC, Chang YH, Shyu WC, Lin SZ: Human umbilical cord mesenchymal stem cells: a new era for stem cell therapy. Cell Transplant 2015;24:339-347.

-19 Wang Y, Han Z, Ma J, Zuo C, Geng J, Gong W, Sun Y, Li H, Wang B, Zhang L, He Y, Han Z: A toxicity study of multiple-administration human umbilical cord mesenchymal stem cells in cynomolgus monkeys. Stem Cells Dev 2012;21:1401-1408.

20 Shi M, Liu ZW, Wang FS: Immunomodulatory properties and therapeutic application of mesenchymal stem cells. Clin Exp Immunol 2011;164:1-8.

21 Sotiropoulou PA, Perez SA, Gritzapis AD, Baxevanis CN, Papamichail M: Interactions between human mesenchymal stem cells and natural killer cells. Stem Cells 2006;24:74-85. 